\title{
Placenta, Transcortin, and Localized Immune Response
}

\author{
Seymour Werthamer, Shanthi Govindaraj, and Leonard Amaral \\ From the Department of Pathology and Clinical Laboratories, The Methodist \\ Hospital, Brooklyn, New York 11215 and the Department of Pathology, \\ State University of New York Downstate Medical Center, Brooklyn, New York 11203
}

\begin{abstract}
A в S TRACT The syncytiotrophoblastic cells of the human placenta contain a cytoplasmic protein recognized by fluorescein-labeled transcortin-specific antibody. Purification of this protein from human placenta, by those methods employed for the purification of human plasma transcortin, yielded a protein that exhibited antigenic and biochemical similarity to plasma transcortin. Placental transcortin differs from plasma transcortin in that it has a smaller sedimentation coefficient (3S vs $3.75 \mathrm{~S}$ ) and binds cortisol less strongly. This purified protein is able to block the phytohemagglutinin response of maternal lymphocytes even more than serum transcortin. It is postulated that the biological role may be that of inhibiting the maternal cell-mediated immune response to the presence of the antigenic conceptus.
\end{abstract}

\section{INTRODUCTION}

The mammalian conceptus is antigenically different from the mother, and yet immunological rejection of the fetus does not normally occur. Lack of immunological rejection has generally been attributed to depressed cell-mediated phenomena of the mother during pregnancy (1-5). Evidence has been presented demonstrating factors present in pregnancy plasma capable of limiting as well as inhibiting those in vitro responses representative of cell-mediated immunity (6-9). Hormones such as gonadotropin $(10,11)$, corticosteroids (12), progesterone (13), plasma proteins $(14,15)$, and serum blocking antibodies $(16,17)$ are synthesized by the placenta and have been demonstrated to suppress in vitro responses associated with cell-mediated immunity.

The steroid hormone, cortisol, elevated to very high levels with continuation of pregnancy, is a potent suppressor of cell-mediated phenomena. The repressive action of cortisol on the lymphocyte is considered to be dependent upon the presence of a specific cortisol receptor protein of the lymphocyte's cytoplasm $(18-20)$. We

Received for publication 31 December 1974 and in revised form 21 November 1975. have recently demonstrated that the major cortisolbinding protein of the human lymphocyte is chemicophysically similar and immunologically identical to transcortin, the cortisol-binding globulin of human plasma (21). Furthermore, this protein is actively transported into the lymphocyte ${ }^{1}$ and is postulated to interfere with the protein-synthetic apparatus of the cell (22). Transcortin is markedly and continuously increased during pregnancy $(23,24)$. This increase is due to increased synthesis induced by elevations of plasma estrogens $(25,26)$ and occurs exclusively in the liver $(27,28)$. It is possible, therefore, that increased levels of transcortin could result in the suppression of cell-mediated immunity. If transcortin has a central role in dampening the cell-mediated immune activity of those lymphocytes responding to the presence of the antigenic fetus, it seemed logical to us to expect that perhaps the action of transcortin might be more immediately potent if its site of synthesis and release were the placenta. Placental synthesis of transcortin would also result in delimiting the activity of $\mathrm{T}$ lymphocytes in the vicinity of the placenta, with perhaps lesser systemic effects on the mother, for she must continue to have operable "immunological surveillance."

This study investigated the question of whether transcortin is present in the fetal placental unit and whether the purified placental transcortin had any inhibitory action on the phytohemagglutinin (PHA) ${ }^{2}$-induced blast transformation of human lymphocytes. Direct measurements of lymphocyte intracellular transcortin of the normal and pregnant woman correlate well with increases in plasma transcortin in pregnancy and, coupled with the findings that the placenta contains a protein similar to plasma transcortin and capable of inhibiting the lymphocyte's response to PHA, the important role of transcortin in the prevention of immunological rejection of the human fetus receives considerable support.

\footnotetext{
${ }^{1}$ Werthamer, S., R. Khaund, and L. Amaral. Submitted for publication.

${ }^{2}$ Abbreviations used in this paper: HAP, hydroxylapatite ; PHA, phytohemagglutinin.
} 


\section{METHODS}

The purification of human plasma transcortin, its characterization, and the preparation of a transcortin-specific antibody have been previously described (21).

In situ localization of intracellular transcortin. Smears of human lymphocytes or frozen sections of human placenta were air-dried, immersed in ice-cold acetone, and coated with fluorescein-labeled transcortin-specific antibody (21). After suitable washing with phosphate-buffered saline, the slides were mounted with a mixture of $50 \%$ glycerol-phosphate saline solution and studied with a Leitz fluorescence microscope (E. Leitz, Inc., Rockleigh, N. J.).

Quantitation of lymphocyte intracellular transcortin. Smears of peripheral blood of normal healthy women and pregnant women of well-defined trimesters were made and coated with serial dilutions of the fluorescein-labeled transcortin antibody. Microscopic fields were first studied under dark field illumination and the number of lymphocytes present was recorded. This same field was then examined under ultraviolet illumination and the number of the lymphocytes of that field exhibiting positive fluorescence was recorded. The highest dilution of the fluorescein-labeled antibody yielding fluorescence in $50 \%$ of the lymphocytes examined $\left(D_{50}\right)$ was employed as an index denoting the relative amount of lymphocytes intracellular transcortin. In this manner, normal, pregnant and post-partum peripheral lymphocytes were examined.

Preparation of placental cytosol. Full-term placentas were cut into slices approximately $100 \mathrm{~g}$ each, the slices were thinly minced, and the minced pieces (about $1-2 \mathrm{~mm}$ in average thickness) were rinsed eight times with ice-cold saline or until the last rinse exhibited no erythrocytes and the tissues contained no demonstrable hemoglobin. Minced placental tissues were homogenized at $4^{\circ} \mathrm{C}$ in $1 \mathrm{mM}$ phosphate, $\mathrm{pH} 7.4$, with a conical hand-driven homogenizer. The crude homogenate was then filtered through two layers of cheesecloth and then centrifuged at $10,000 \mathrm{~g}$. The supernate was then centrifuged at $105,000 \mathrm{~g}$ for $3 \mathrm{~h}$, thus yielding a placental cytosol. This cytosol was lyophilized, dissolved in water, and dialyzed against two changes of 4 liters of $1 \mathrm{mM}$

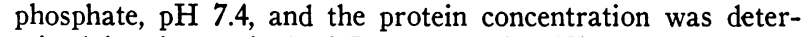
mined by the method of Lowry et al. (29).

Determination of placental intracellular transcortin. $\mathrm{Cy}-$ tosol was assayed for transcortin by the Ouchterlony doublediffusion procedures (21).

Determination of cortisol-binding activity by placental cytosol. $0.5-\mathrm{ml}$ aliquots of placental cytosol (approximately $1 \mathrm{mg}$ of protein $/ \mathrm{ml}$ ) were incubated with $10^{6} \mathrm{cpm}$ of $\left[{ }^{3} \mathrm{H}\right]-$ cortisol, sp act $5,000 \mathrm{mCi} / \mathrm{mM}$, (Schwarz/Mann Div., Becton, Dickinson \& Co., Orangeburg, N. Y.) for $1 \mathrm{~h}$ at $4^{\circ} \mathrm{C}$. Determination of specific cortisol-binding activity was determined by passing the above incubation mixture through a buffer-equilibrated G-25 Sephadex column $(45 \times 0.5 \mathrm{~cm})$ in accordance with the method of DeMoor et al. (30). Radioactivities of the fractions collected were assayed by a Picker Ansitron II liquid scintillation counter (Picker Corp., Cleveland, Ohio) after the addition of $15 \mathrm{ml}$ of Bray's scintillant to the vials containing the fractions.

Purification of placental transcortin. The entire cytosol preparation of one full-term placenta was incubated with $\left[{ }^{3} \mathrm{H}\right]$ cortisol under conditions previously stated. Purification of placental transcortin was accomplished by the same procedure employed and described by Muldoon and Westphal (31) for the purification of plasma transcortin. Details pertaining to the various steps of purification are given in the text and appropriate legends of the figures.

Behavior of placental transcortin in ultracentrifugation in sucrose gradients. Sucrose gradients of 5-20\% were prepared in $1 \mathrm{mM}$ phosphate, $\mathrm{pH} 7.4$. Aliquots of $0.5 \mathrm{ml}$ of various preparations of placental transcortin obtained from each step of the purification procedures were carefully layered on top of the gradients and the gradients were centrifuged in a SW-65 rotor at $60,000 \mathrm{rpm}$ for $21 \mathrm{~h}$ at $5^{\circ} \mathrm{C}$ in a Beckman L-2-75 B ultracentrifuge (Beckman Instruments, Inc., Spinco Div., Palo Alto, Calif.). Fractionation of the gradient into 30 equal fractions was performed with the aid of an Isco sucrose gradient-ultraviolet monitoring system (Instrumentation Specialties Co., Lincoln, Neb.) (at $280 \mathrm{~nm})$, and analysis of radioactivity representing $\left[{ }^{3} \mathrm{H}\right]-$ cortisol bound to protein was obtained after the addition of $15 \mathrm{ml}$ of Bray's scintillant. Standardization of the procedure required for the estimation of sedimentation coefficients has been previously described (21).

Disc-acrylamide electrophoresis of purified placental transcortin. $0.1 \mathrm{mg}$ of the purified hydroxylapatite (HAP) II fraction was layered on top of disc acrylamide electrophoretic columns $(0.5 \times 7.0 \mathrm{~cm})$ containing a $10 \%$ acrylamide separation gel. Electrophoresis was conducted as described by Ornstein (32) and Davis (33).

The effect of placental transcortin on PHA-induced blast transformation by human lymphocytes. Human lymphocytes, purified by methods previously described $(22,34)$ were suspended in autologous plasma at a concentration of $25 \times 10^{6}$ cells $/ \mathrm{ml}$ of plasma. $0.1 \mathrm{ml}$ of these suspensions was added to $1 \mathrm{ml}$ of TC-199 medium containing penicillin (100 $\mathrm{U} / \mathrm{ml})$ and streptomycin $(10 \mathrm{mg} / \mathrm{ml})$ and $0.25 \mathrm{ml}$ of PHA-P (Difco Laboratories, Detroit, Mich.). To half of these cultures, approximately $0.1 \mathrm{mg}$ of purified placental transcortin was added. All cultures were incubated for up to 3 days at $37^{\circ} \mathrm{C}$ in a $5 \% \quad \mathrm{CO}_{2}$ atmosphere mixture. At the end of designated intervals each of the cultures received $1 \mu \mathrm{Ci}$ of $\left[{ }^{3} \mathrm{H}\right]$ thymidine (sp act $33 \mathrm{Ci} / \mathrm{mM}$ ) and the cultures were incubated for $2 \mathrm{~h}$ at $37^{\circ} \mathrm{C}$. Incorporation of $\left[{ }^{3} \mathrm{H}\right]$ thymidine by cultured cells was determined by methods previously described $(22)$. In addition, the cultured cells were smeared, and the percentage of lymphocytes transformed was determined by microscopic evaluation by two independent investigators. In all cases, agreement of such analysis did not deviate by more than $\pm 3 \%$ of the mean between the two sets of analysis.

\section{RESULTS}

\section{Quantitation of intracellular lymphocyte} transcortin

Previously we demonstrated that the human lymphocyte contains within its cytoplasm a protein species with many of the physicochemical properties of transcortin (21). In situ identification of this transcortinlike protein was afforded by the application of a fluorescein-labeled transcortin antibody to smears of peripheral blood lymphocytes. It was noted that almost all of the fluorescence was limited to the cytoplasmic rim of the lymphocyte. Controls demonstrated that such fluorescence was not due to membrane-bound transcortin (21).

We have attempted to measure the level of intracellular transcortin of peripheral blood lymphocytes during pregnancy. Our reasons for attempting this analysis stem from studies demonstrating that trans- 


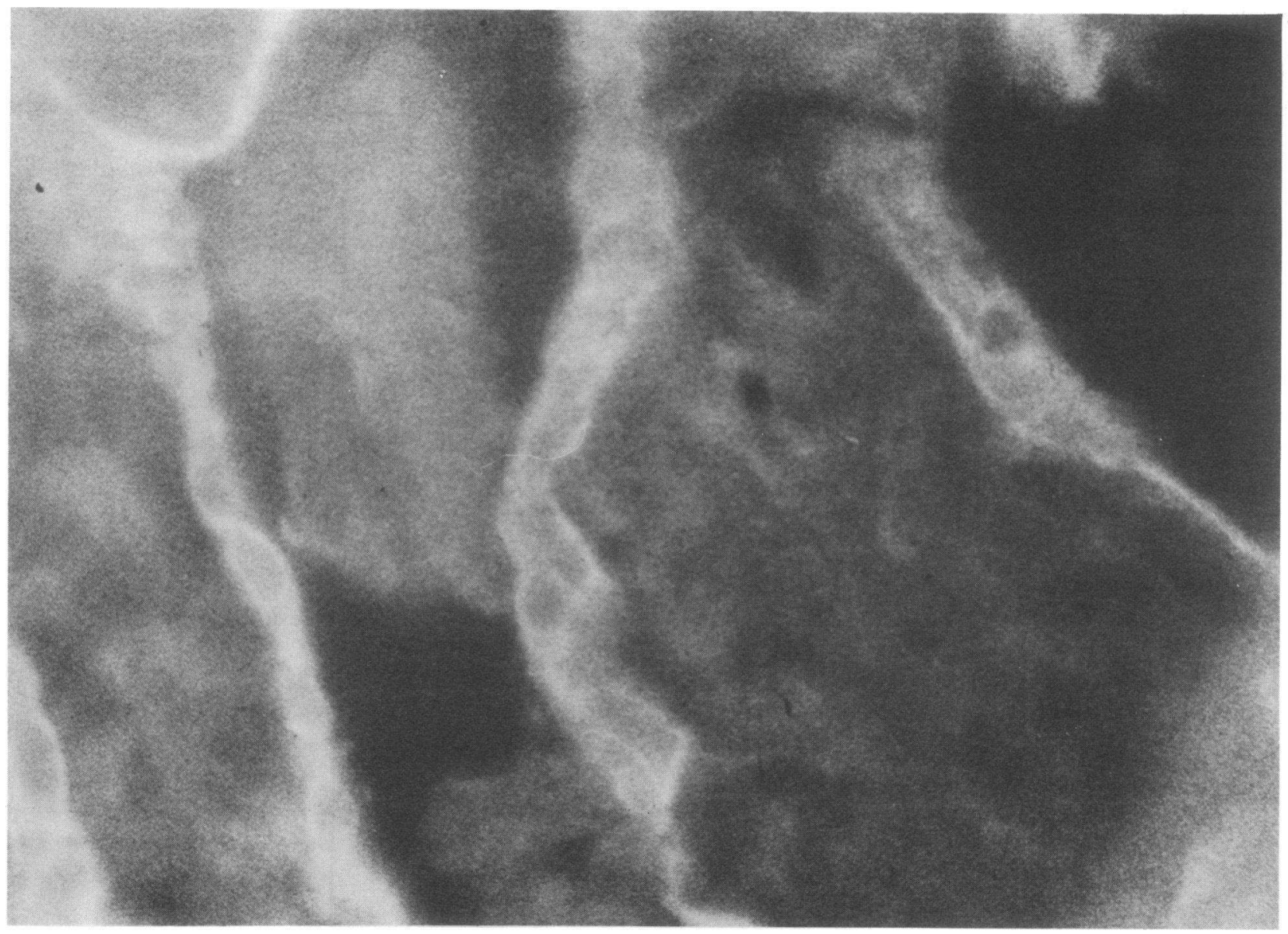

FIGURE 1 In situ localization of transcortin within the cytoplasm of placental cells. Frozen sections, approximately $5 \mu \mathrm{m}$ thick, were prepared from pieces of fresh, extensively salinewashed, full-term placenta. Diluted fluorescein-labeled transcortin antibody was layered as described previously. Note that fluorescence is primarily found in the cytoplasm of the syncytiotrophoblastic cells.

cortin levels are markedly elevated during pregnancy $(23,24)$. Since transcortin is found within the lymphocyte and since lymphocytes do not appear to synthesize transcortin, the possibility that increased plasma levels of transcortin would result in increases of intracellular lymphocyte transcortin seemed worthy of investigation. The use of serial dilutions of the fluoresceinlabeled transcortin antibody to quantitate the relative level of lymphocyte intracellular transcortin illustrates that this level increases with continuation of pregnancy and reaches a maximum during the third trimester (Table I). It should be noted from the data presented that the range of $D_{s o}$ is rather narrow within the normal (nonpregnant) group of women $(1: 40-1: 80)$. However, during the first trimester the Dso increases as well as its range. The range of $D_{50}$ continues to increase during the second trimester. It is during the third trimester, however, that the levels of intracellular transcortin are truly significantly different from those of the normal. Within this group, 12 of the 14 individuals had a Dso of $1: 640$. Immediately before parturition, the intracellular transcortin level drops to within the normal range.

\section{In situ localization of transcortin within placental cells}

Biosynthetically plasma transcortin has been considered to originate exclusively in the liver $(27,28)$. Furthermore, administration of estrogens or their synthetic analogues results in a maximal twofold increase in plasma transcortin levels (35), suggesting that the maximum synthesis in the liver might be limited. However, transcortin levels in pregnant women reach much higher levels $(23,24)$, suggesting in turn that perhaps another organ or organs might be synthesizing this protein as well. To determine whether the placenta might synthesize and/or contain transcortin, we applied the fluorescein-labeled transcortin antibody to frozen 
sections of a full-term human placenta. Fig. 1 illustrates the presence of transcortin within the cytoplasm of the syncytiotrophoblastic cells lining the maternal sinus. No other cells of the placenta, except an occasional lymphocyte, exhibit any fluorescence. We have similarly treated a 15-wk placenta obtained surgically and no fluorescence was detected.

\section{Determination of cortisol binding by placental cytosol}

The above studies on the human placenta suggest that placental tissue contains a protein(s) recognized by the transcortin-specific antibody. Additional evidence suggesting that the placenta indeed contains transcortin is provided by the determination of cortisol binding by the G-25 Sephadex filtration of DeMoor et al. (30). From the data presented in Fig. 2, it is clear that the placental cytosol contains species capable of rigorously binding cortisol (front-running radioactivity peak).

\section{Purification of placenta transcortin}

The above findings suggest that the placenta contains species of protein that bind cortisol and are recognized by a transcortin-specific antibody. To determine whether the above species are indeed transcortin, their purification was attempted via the methods used for the purification of transcortin. Passage of $\left[{ }^{3} \mathrm{H}\right]$ cortisol-placental cytosol through a water-equilibrated DEAE column and subsequent washing of the column with water, followed by elution with buffer, yielded an $\left[{ }^{3} \mathrm{H}\right]$ cortisol elution profile depicted in Fig. 3. Under the elution conditions listed in the legend of Fig. 3, a single radioactive peak coinciding with an optical density peak at

TABLE I

Quantitation of Lymphocyte Intracellular Transcortin of Normal and Pregnant Females

\begin{tabular}{lcc}
\hline & $\begin{array}{c}\text { Number } \\
\text { of } \\
\text { individuals }\end{array}$ & Range of $\mathbf{D}_{\mathbf{5 0}}{ }^{*}$ \\
\hline Normal & 34 & $1: 40-1: 80$ \\
First trimester & 26 & $1: 80-1: 320$ \\
Second trimester & 25 & $1: 80-1: 640$ \\
Third trimester & $34 \ddagger$ & $1: 320-1: 640$ \\
At parturition & 3 & $1: 80-1: 160$ \\
2 days after delivery & 9 & $1: 40-1: 80$ \\
\hline
\end{tabular}

The significant difference between normal and $3 \mathrm{rd}$ trimester values as determined by Student $\mathrm{t}$ test is $P<0.02$.

* Range of dilution of fluorescein-labeled antibody that yielded approximately $50 \%$, of the lymphocytes demonstrating fluorescence. Lymphocytes of a single field were first examined under dark field microscopy and then under ultraviolet excitation. $\ddagger 20$ of 34 individuals had a $D_{50}$ of $1: 640$.

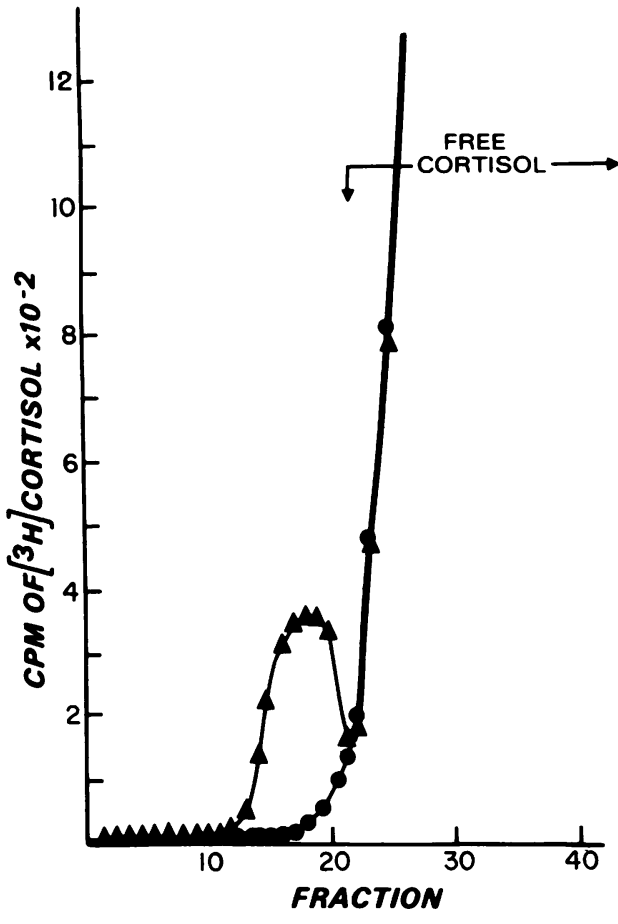

Figure 2 G-25 Sephadex assay of cortisol binding by placental cytosol. $1 \mathrm{mg}$ of placental cytosol was incubated with $10^{\circ} \mathrm{cpm}$ of $\left[{ }^{3} \mathrm{H}\right.$ ] cortisol ( $\mathrm{sp}$ act $5,000 \mathrm{Ci} / \mathrm{mM}$ ) at $4^{\circ} \mathrm{C}$ for $60 \mathrm{~min}$. The mixture was passed through a column of G-25 Sephadex $(45 \times 0.5 \mathrm{~cm})$ and elution was conducted with $\mathrm{mM}$ phosphate, $\mathrm{pH}$ 7.4. Fractions of $1 \mathrm{ml}$ were collected and assayed for radioactivity. Controls lacking placental cytosol, but instead containing $1 \mathrm{mg}$ of heat-denatured bovine albumin were similarly processed. The fractions between the arrows denote the elution of free cortisol. The front-running radioactive peak represents $\left[{ }^{8} \mathrm{H}\right]$ cortisol bound to some species of the cytosol $(\boldsymbol{\Delta}-\boldsymbol{\Delta}-\boldsymbol{\Delta})$. Incubations con-

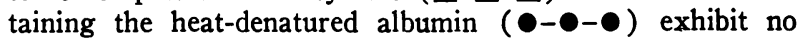
front-running radioactive peak.

$280 \mathrm{~nm}$ was obtained. After the pooling of the fractions under the radioactive peak, the pooled fractions (after DEAE) were lyophilized and dialyzed against $\mathrm{mM}$ phosphate, $\mathrm{pH}$ 7.4. G-25 Sephadex filtration procedures demonstrated that the radioactivity of the post-DEAE pooled fraction represented protein-bound $\left[{ }^{3} \mathrm{H}\right]$ cortisol. This pooled post-DEAE fraction was split into two portions, one rapidly frozen and stored at $-70^{\circ} \mathrm{C}$, the other portion passed through a HAP column. Elution of the applied material yielded two radioactivity peaks labeled HAP I and HAP II in Fig. 4. Only the HAP II fraction exhibited strong cortisol-binding activity, demonstrable via G-25 Sephadex methods, as previously described. This HAP II fraction was passed through two additional HAP columns, the last of which exhibited a single $\left[{ }^{3} \mathrm{H}\right]$ cortisol peak coinciding with a single optical density peak at $280 \mathrm{~nm}$. Lyophilization with subsequent dialysis against saline was carried out. 


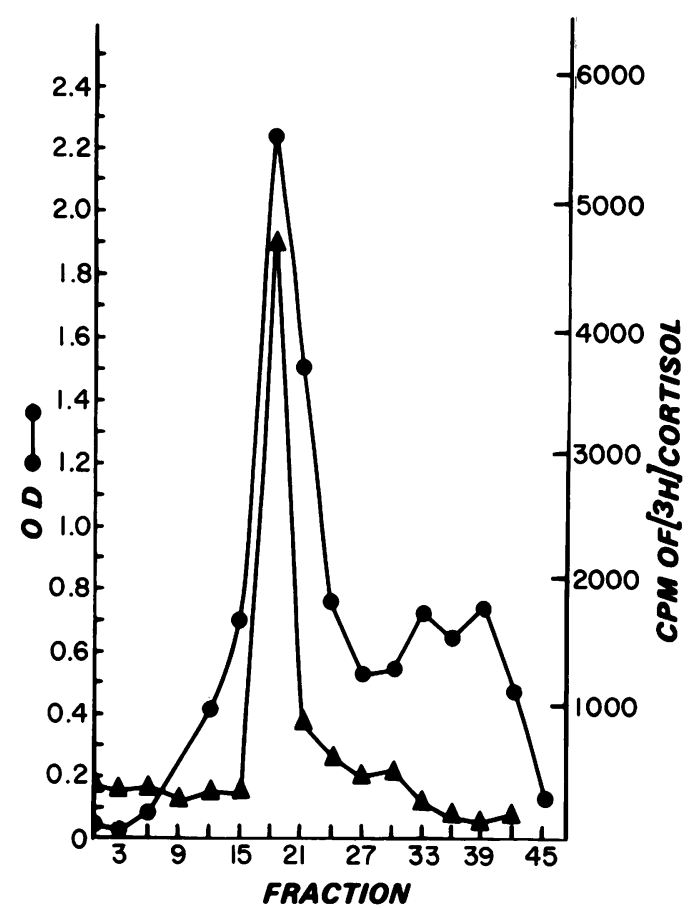

FIgURE 3 Elution of $\left[{ }^{3} \mathrm{H}\right]$ cortisol-placental cytosol from water-equilibrated DEAE columns. Placental cytosol (approximately $300 \mathrm{ml}$ ) was incubated with $10^{\circ} \mathrm{cpm}$ of $\left[{ }^{8} \mathrm{H}\right]-$ cortisol for $1 \mathrm{~h}$ at $4^{\circ} \mathrm{C}$. This mixture was loaded onto a water-equilibrated DEAE column (Pharmacia DEAE-52) $(70 \times 1.5 \mathrm{~cm})$ and subsequently washed with water until little radioactivity was present in the eluate. Elution was conducted via a linear gradient formed with 1 liter each of $1 \mathrm{mM}$ phosphate, $\mathrm{pH} 8$, and $0.5 \mathrm{M}$ phosphate, $\mathrm{pH}$ 5.5. Fractions consisting of about $10 \mathrm{ml}$ were collected and radioactivity was determined.

Comparison of purified placental cortisol-binding protein to purified plasma transcortin and its partial characterization

Ouchterlony studies. That this post-HAP fraction contained transcortin is demonstrated by the results of double diffusion-Ouchterlony procedures. Fig. 5 illustrates that purified human plasma transcortin forms two precipitin lines. The existence of a second precipitin is not due to an impurity but to the formation of a dimer by the transcortin molecule (21). The wells containing HAP II fractions demonstrated the formation of precipitin lines contiguous with those formed between the antibody- and transcortin-containing wells. The wells containing HAP I pooled fractions failed to develop any precipitin. The well containing the placental cytosol yielded multiple precipitin lines. Whether these precipitin lines are due to polymers or variations in the transcortin-like molecule due to degradation or additional transcortin-like species cannot at this time be determined.

Sucrose gradient centrifugation analyses. Determin-

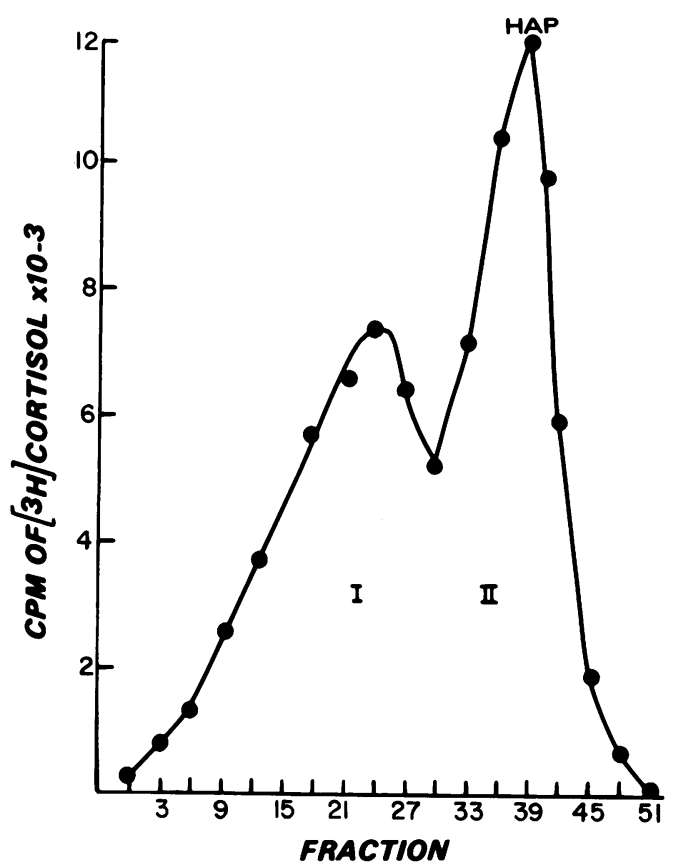

FIgURE 4 Application and elution of post-DEAE [ $\left.{ }^{8} \mathrm{H}\right]-$ cortisol placental mixture from HAP columns. Lyophilized post-DEAE fraction, dissolved in $50 \mathrm{ml}$ of $1 \mathrm{mM}$ phosphate was loaded onto an HAP column $(70 \times 0.5 \mathrm{~cm})$ and

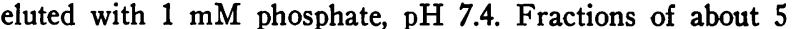
$\mathrm{ml}$ were collected and assayed for radioactivity.

ation of sedimentation coefficients for the placental intracellular transcortin during various stages of its purification was accomplished. Fig. 6 illustrates that plasma transcortin contains a single $\left[{ }^{8} \mathrm{H}\right]$ cortisol peak corresponding to a sedimentation coefficient of 3.6-3.8. Similar treatment of the placental cytosol yields two radioactive peaks of 3 and $4.5 \mathrm{~S}$ (Fig. 7). The $3 \mathrm{~S}$ peak is very broad and hence any minor species sediment-

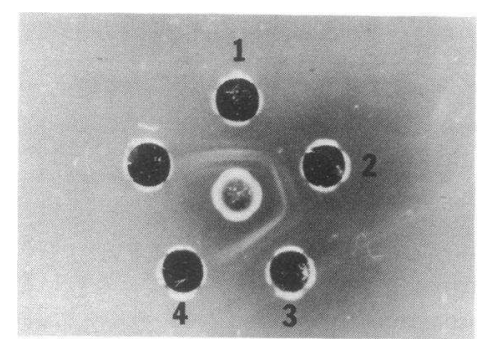

FIgURE 5 Demonstration of transcortin-like protein in the post-HAP fraction of placental cytosol by transcortin-specific antibody. Central well contains transcortin-specific antibody. Well 1 contains placental cytosol; well 2 contains purified transcortin; well 3 contains purified, postHAP II placental fraction. Well 4 contains HAP I fraction. Note the continuous precipitin line closest to central well. Additional outer precipitin lines are visible. Such precipitin lines are not due to impurities but rather to degrees of polymerization of transcortin-like proteins (see reference 21). 
ing as a plasma transcortin component would be masked. However, the sedimentation profile obtained after the first passage through HAP columns yields a profile similar to that of the cytosol (Fig. 8). It should be noted that no sedimentation activity peak corresponding to that of plasma transcortin was evident at any point during purification.

Disc acrylamide electrophoretic analysis. In accordance with differences in sedimentation behavior in sucrose gradients between the HAP II fraction and plasma transcortin, Fig. 9 illustrates that HAP II fraction and transcortin are electrophoretically dissimilar. It is clear that HAP II fraction migrates in this system with more mobility than purified transcortin.

\section{Effect of purified placental transcortin} on the PHA response

To determine whether the placental fraction (exhibiting many of the characteristics of transcortin) inhibits in vitro responses associated with cell-mediated immunity, human lymphocytes, obtained from normal women, were incubated with and without placental fraction HAP II or with purified human transcortin to which cortisol was tightly bound. The results, presented

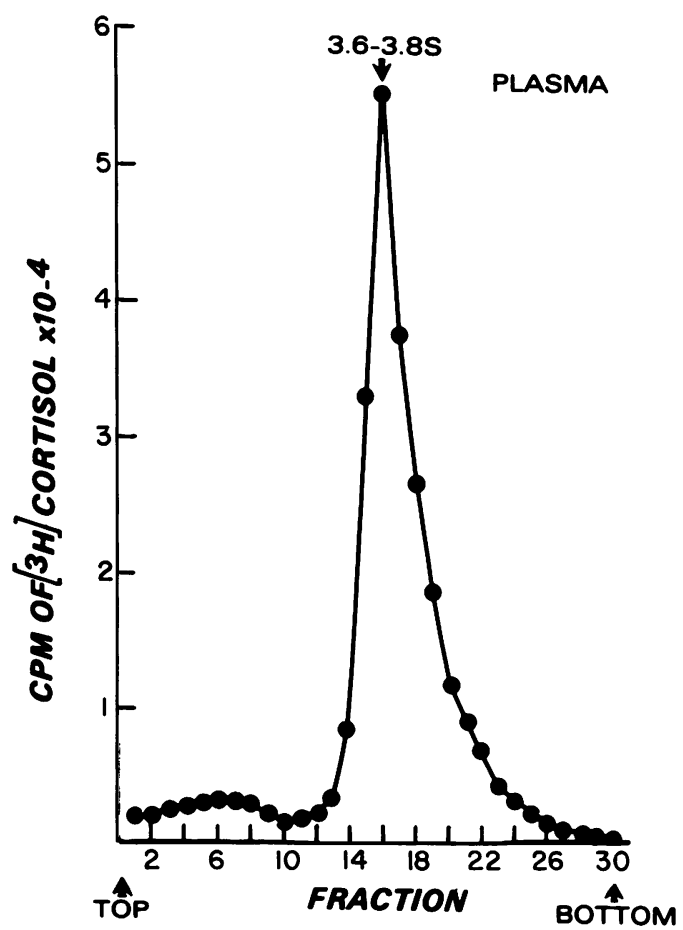

FIGURE 6 Sucrose gradient centrifugation of $\left[{ }^{2} \mathrm{H}\right]$ cortisolplasma transcortin. $0.5 \mathrm{ml}$ of a mixture of plasma transcortin and $\left[{ }^{3} \mathrm{H}\right]$ cortisol was layered on top of a $5-20 \%$ sucrose gradient ( $1 \mathrm{mM}$ phosphate, $\mathrm{pH} 7.4$ ) and centrifuged at $60,000 \mathrm{rpm}$ for $21 \mathrm{~h}$. Fractionation and analysis of $\left[{ }^{3} \mathrm{H}\right]$ cortisol activity of these gradients have been previously described (21).

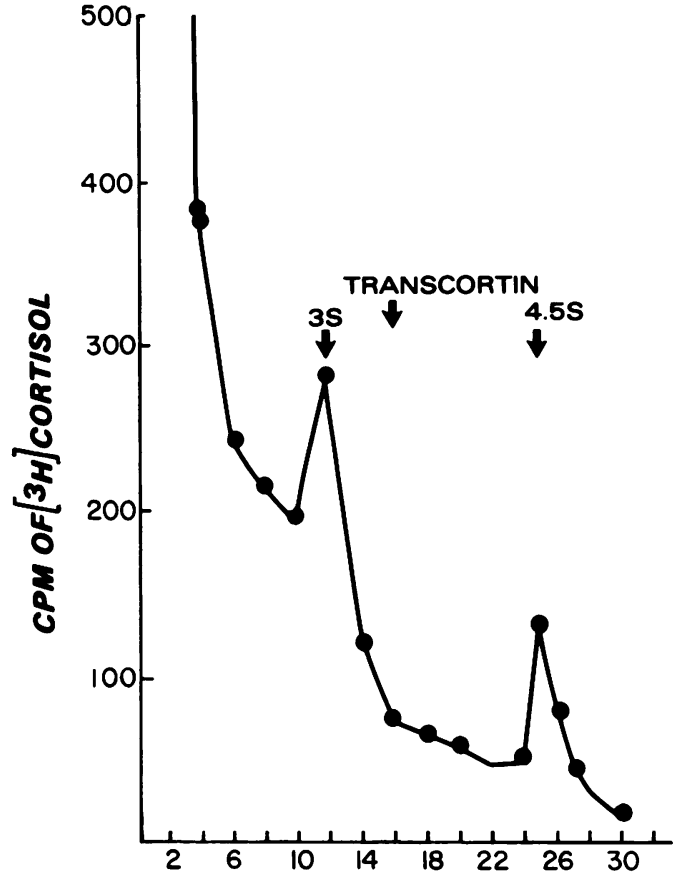

FIGURE 7 Ultracentrifugation of placental cytosol in sucrose gradients. Conditions are as previously described. Note that two radioactive peaks, corresponding to sedimentation constants of 3 and $4.5 \mathrm{~S}$, are present. The position fraction where transcortin is expected contains no radioactive peak.

in Table II, illustrate that the transformation of lymphocytes by PHA is inhibited by placental factor HAP II. The effect of the above on the incorporation of $\left[{ }^{3} \mathrm{H}\right]$ thymidine into DNA is presented in Table III. It is evident from the data presented that the placental factor HAP II inhibits the incorporation of $\left[{ }^{3} \mathrm{H}\right]$ thymidine by $78 \%$. Control experiments demonstrate that the inhibition of $\mathrm{PHA}$ was not due to the precipitation of PHA by the protein added, as shown in Table III.

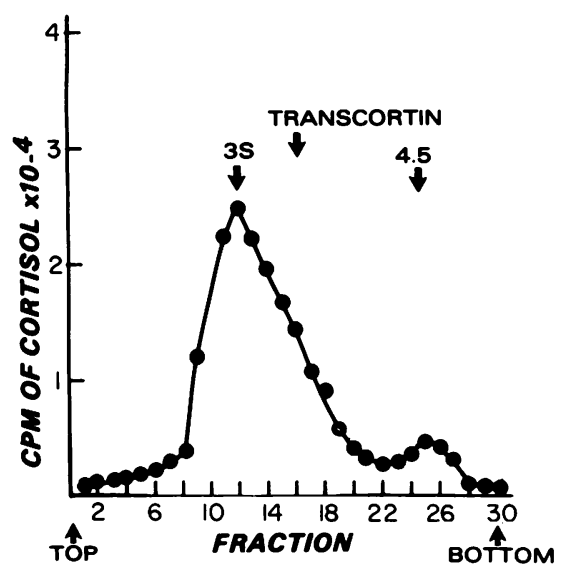

FIgURE 8 Sucrose gradient ultracentrifugation of postHAP fraction II. 


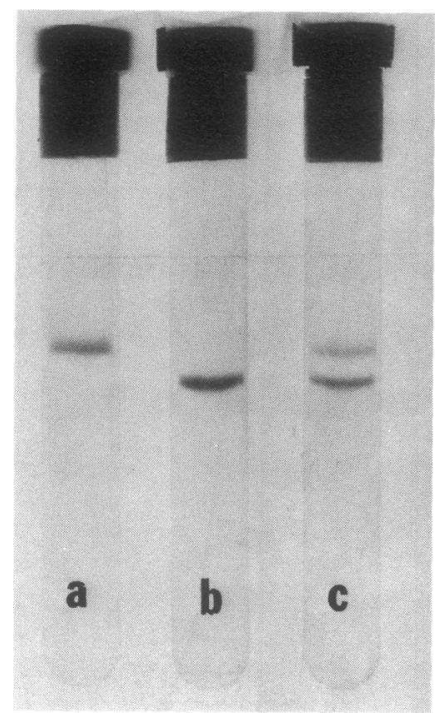

FIGURE 9 Disc-acrylamide electrophoresis of purified transcortin and post-HAP fraction II. Approximately $300 \mu \mathrm{g}$ of purified transcortin (gel $a$ ) and post-HAP fraction II (gel b) were electrophorised. A mixture of $150 \mu \mathrm{g}$ each of purified transcortin and post-HAP fraction II were also electrophorised (gel $c$ ). Note that the placental fraction has a greater mobility than purified transcortin.

In addition, the presence of transcortin inhibits such incorporation by only $35 \%$.

\section{DISCUSSION}

The results presented in this study demonstrate that the cytoplasm of syncytiotrophoblastic cells of the human placenta contains a protein with immunologic and physicochemical characteristics similar to that of plasma transcortin. However, this molecule differs from trans-

TABLE II

The Effect of Purified Placental Transcortin on the Transformation of Human Lymphocytes by PHA

\begin{tabular}{lrcc}
\hline & \multicolumn{3}{c}{ Blast transformed } \\
\cline { 2 - 4 } & Day 1 & Day 2 & Day 3 \\
\hline & \multicolumn{3}{c}{$\%$} \\
Control PHA & 16 & 51 & 68 \\
Placental transcortin & 8 & 34 & 40 \\
\hline
\end{tabular}

Human lymphocytes were cultured in medium containing PHA for intervals of 1,2 , and 3 days in the presence and absence of purified placental transcortin (HAP II fraction) at a protein concentration of $0.1 \mathrm{mg} / \mathrm{ml}$ of medium. At the end of 1,2 , and 3 days of culture, aliquots of $0.1 \mathrm{ml}$ of the culture were smeared onto glass slides, air-dried, and stained. All immature lymphocytes were designated as "transformed." The above experiments were repeated twice with lymphocytes obtained from two other healthy pregnant women. Similar results were obtained.
TABLE III

The Effect of Purified Placental Transcortin on the Incorporation of $\left[{ }^{3} H\right]$ Thymidine by Lymphocytes Cultured in the Presence of $P H A$

\begin{tabular}{lcc}
\hline & {$[\mathrm{H}]$ Thymidine } & Inhibition \\
\hline & $\begin{array}{c}c \text { cpm } / 10 \mathrm{10} \\
\text { lymphocytes }\end{array}$ & $\%$ \\
Control (no PHA) & 104 & - \\
PHA & 2,430 & - \\
PHA \& placental transcortin & 535 & $78 \%$ \\
PHA \& transcortin & 1,580 & $35 \%$ \\
PHA for 2 h & 2,515 & - \\
PHA for 2 h, then placental & & \\
transcortin added & 475 & $81 \%$ \\
\hline
\end{tabular}

Human lymphocytes were incubated in medium with and without PHA. To other cultures containing PHA either purified placental transcortin or purified plasma transcortin was added to a final concentration of $0.1 \mathrm{mg} / \mathrm{ml}$ of medium. In addition, other cultures were incubated with PHA for $2 \mathrm{~h}$ before the cultures were centrifuged, and the cells suspended with fresh medium. To experimental cultures, purified placental transcortin was added to a final concentration of $0.1 \mathrm{mg} / \mathrm{ml}$ of medium. At the end of 3 days of incubation, the cultures were agitated, and aliquots transferred to culture tubes containing $1 \mu \mathrm{Ci}$ of $\left[{ }^{3} \mathrm{H}\right]$ thymidine. These cultures were incubated for an additional $2 \mathrm{~h}$ and then centrifuged, and the pellets were suspended in $0.5 \mathrm{ml}$ of saline. To each, ice-cold $10 \%$ trichloracetic acid was added, and the precipitates were collected by Millipore filtration, dried, and immersed into vials containing Liquiflor, and the activities of tritium were determined with a scintillation counter. All cultures were performed in triplicate. The maximum deviation did not exceed $4 \%$. The above data was obtained from one of four such experiments.

cortin in that it has a smaller sedimentation coefficient (3S) than plasma transcortin (3.75S). In crude preparations an additional cortisol-binding component with a sedimentation coefficient of $4.5 \mathrm{~S}$ is present. (This 4.5 $\mathrm{S}$ species, we feel, is probably a dimer). The presence of this partially purified protein was also shown in this study to suppress blast transformation of normal lymphocytes.

That the protein purified is not a plasma transcortin contaminant, due to inadequate mincing and washing procedures, and is indeed obtained from placental tissues may be concluded from: In situ localization of the molecule within the syncytiotrophoblastic cells of frozen placental tissues sectioned at a thickness of $5 \mu \mathrm{m}$. At this thickness the cells depicted are true sections of cells. The physicochemical characteristics, such as behavior in sucrose gradients and electrophoretic fields, are different from purified plasma transcortin. And observed differences that cannot be due to the purification procedure, since such procedures in our hands do not 
and have not altered the physicochemical of purified plasma transcortin.

These results suggest that the placenta contains a protein similar if not identical to plasma transcortin, and that its function might be that of limiting cellmediated responses of maternal lymphocytes to the presence of the antigenic fetal placenta.

In our previous studies, we have suggested that plasma transcortin may be transported into the human lymphocyte $(22,34)$ and that the transcortin present within the cytoplasm of the human lymphocyte is smaller than plasma transcortin and very similar in its physicochemical characteristics to partially purified placental transcortin (21). Studies submitted elsewhere provide strong support for this contention by showing that cultured human lymphocytes of the cell line RPMI-1788 transport this protein from the medium to their cytoplasm. ${ }^{1}$ We have suggested that soon after the transport of transcortin-cortisol complexes into the lymphocyte, an enzyme acts on this complex, thereby removing cortisol (this cortisol is rapidly and actively extruded [34]) and thereby yielding a small polypeptide (21). After this enzymatic action, the resulting transcortin has a smaller cortisol-binding capacity and a smaller sedimentation coefficient. We have postulated that this modified transcortin inhibits the synthesis of lymphocyte protein $(21,22)$. We feel that, unlike the lymphocyte, biosynthesis of the placental transcortin possibly occurs within placental cells. To date, however, only the liver has been identified as the exclusive site of transcortin biosynthesis $(27,28)$.

It is presumed that placental transcortin, like transcortin in the liver, is induced by maternal secretions of estrogen. Support for this hypothesis may be found in those studies that demonstrate that the biosynthesis of transcortin is induced by estrogen and that increases in plasma estrogen during pregnancy are paralleled by increases in maternal plasma transcortin $(25,26)$. We feel that during the first trimester, the increased level of transcortin in maternal plasma is the result of its induced biosynthesis by the liver in response to estrogenic increases. However, the absolute limit of transcortin levels resulting from estrogenic induction is probably equal to that observed in men receiving diethylstilbestrol, about $6-12 \mathrm{mg}$ of transcortin/100 $\mathrm{ml}$ of plasma (35). Since the total level of maternal plasma transcortin is much higher during the second, and still higher during the third trimester (23), this total level may possibly involve transcortin molecules of placental origin.

Although we have not measured plasma transcortin levels before parturition in this study, we have measured the level of lymphocyte intracellular transcortin during pregnancy. Our results suggest that during gestation peripheral lymphocytes contain increasing levels of cytoplasmic transcortin. These increases parallel those observed in plasma and may result from an increase in transcortin transport into the lymphocyte. However, unlike the transport of plasma transcortincortisol complexes, only the modified transcortin of placental origin enters the lymphocyte. It is this modified protein that can limit the cell-mediated immune response to a much greater degree than the unadulterated transcortin-cortisol complex.

The presence of large amounts of transcortin within placental cells at time of parturition might at first seem to contradict the above hypothesis. It is suggested, however, that the transcortin observed in full-term placental cells might simply reflect an accumulation due to diminished secretion of this protein. This diminished secretion might be the result of an increase in the rate that estrogens are metabolized by the placenta. Support for this contention is provided by those studies that show that in liver, estrogen controls the release of transcortin to the circulatory system (27). Accordingly, our hypothesis would then predict that maternal cellmediated immunity would now be fully operational. At this point, the placenta and fetus are rejected much as any foreign antigenic tissue would be rejected in the mammal. Evidence of such cell-mediated responses occurring at this time are routinely found in uterine tissues (36).

The above general theory is far from proved. Our studies only support the general theory at critical points. It remains for future studies, some in progress, to elucidate further.

\section{ACKNOWLEDGMENTS}

We would like to thank Bennie Denson and Phyllis Seidler for their excellent technical assistance, Dr. Kobkul Lin for her guidance in the immunologic studies, Dr. Robindra Khaund for conducting the PHA studies, Allan Brown for the preparation of the figures, and Janet Mena for the preparation of the manuscript.

\section{REFERENCES}

1. Lichtenstein, M. R. 1942. Tuberculin reaction in tuberculosis during pregnancy. Am. Rev. Tuberc. 46: 89-92.

2. Heslop, R. W., P. L. Krohn, and E. M. Sparrow. 1954. The effect of pregnancy on the survival of skin homographs in rabbits. J. Endocrinol. 10: 325-332.

3. Billingham, R. E. 1964. Transplantation immunity and the maternal-fetal relation. N. Engl. J. Med. 270: 720725.

4. Breyere, E. J., and S. O. Burhoe. 1963. The nature of the "partial" tolerance induced by parity. J. Natl. Cancer Inst. 31 : 179-188.

5. Simmons, R. L. 1972. Histocompatibility antigens and pregnancy. In Transplantation. J. S. Najarian and R. L. Simmons, editors. Lea \& Febiger, Philadelphia. 285297.

6. Hellström, K. E., I. Hellström, and J. Brawn. 1969. Abrogation of cellular immunity to antigenically foreign 
mouse embryonic cells by a serum factor. Nature (Lond.). 224: 914-915.

7. Harrison, M. R. 1972. Immunocompetence of maternal lymphocytes. Lancet. 2: 1319-1320.

8. Kasakura, S. 1971. A factor in maternal plasma during pregnancy that suppresses the reactivity of mixed leukocyte cultures. J. Immunol. 107: 1296-1301.

9. Leikin, S. 1972. The immunosuppressive effect of maternal plasma Proc. Leucocyte Cult. Conf. 6: 725-742.

10. Kaye, M. D., and W. R. Jones. 1971. Effect of human chorionic gonadotropin on in vitro lymphocyte transformation. Am. J. Obstet. Gynecol. 109: 1029-1031.

11. Adcock, E. W., III, F. Teasdale, C S. August, S. Cox, G. Mescia, F. C. Battaglia, and M. A. Naughton. 1973. Human chorionic gonadotropin: its possible role in maternal lymphocyte suppression. Science (Wash.D.C.). $181: 845-847$.

12. Pasqualini, J. R., B. L. Nguyen, F. Uhrich. N. Wiqvist, and E. Diczfalusy. 1970. Cortisol and cortisone metabolism in the human foeto-placental unit at midgestation. J. Steroid Biochem. 1: 209-219.

13. Munroe, J. S. 1971. Progesteroids as immunosuppressive agents. J. Reticuloendothel. Soc. 9: 361-375.

14. Riggio, R. R., J. E. Parillo, Jr., F. G. Bull, G. H. Schwartz, K. H. Stenzel, and A. L. Rubin. 1971. Inhibition of lymphocyte transformation by a placental glycoprotein. Transplantation (Baltimore). 12: 400-401.

15. Cooperband, S. R., H. Bondevik, K. Schmid, and J. A. Mannick. 1968. Transformation of human lymphocytes: inhibition by homologous alpha globulin. Science (Wash. D. C.). $159: 1243-1244$.

16. Bonneau, M., M. Latour, J. P. Revillard, M. Robert, and J. Traeger. 1973. Blocking antibodies eluted from human placenta. Transplant. Proc. 5: 589-592.

17. Hattler, B. G., Jr., C. Karesh, and J. Miller. 1971. Inhibition of the mixed lymphocyte culture response by antibody following successful human renal transplantation. Tissue Antigens. 1: 270-275.

18. Schaumberg, B. P. 1970. Studies of the glucocorticoidbinding protein from thymocytes. I. Localization in the cell and some properties of the protein. Biochim. Biophys. Acta. 214: 520-532.

19. Munck, A., C. Wira, D. A. Young, K. M. Mosher, C. Hallahan, and P. A. Bell. 1972. Glucocorticoid-receptor complexes and the earliest steps in the action of glucccorticoids on thymus cells. J. Steroid Biochem. 3: 567578.

20. Baxter, J. D., A. W. Harris, G. M. Tompinins, and M. Cohn. 1971. Glucocorticoid receptors in lymphoma cells in culture: relationship to glucocorticoid killing activity. Science (Wash. D. C.). 171: 189-191.

21. Werthamer, S., A. J. Samuels, and L. Amaral. 1973. Identification and partial purification of "transcortin"like protein within human lymphocytes. J. Biol. Chem. 248: 6398-6407.
22. Werthamer, S., and L. Amaral. 1971. The response of leukemic lymphocytes to cortisol: a suggested role of transcortin. Blood. 37: 463-472.

23. Rosenthal, H. E., W. R. Slaunwhite, Jr., and A. A. Sandberg. 1969. Transcortin: a corticosteroid-binding protein of plasma. X. Cortisol and progesterone interplay and unbound levels of these steroids in pregnancy. J. Clin. Endocrinol. 29: 352-367.

24. Butler, J., and P. F. Dixon. 1969. The binding of cortisol to $\mathrm{CBG}$ and albumin in plasma from women during the menstrual cycle and in pregnancy. Ann. Endocrinol. 30: 217-221.

25. Rosenthal, H. E., W. R. Slaunwhite, Jr., and A. A. Sandberg. 1969. Transcortin: a corticosteroid-binding protein of plasma. XI. Effects of estrogens or pregnancy in guinea pigs. Endocrinology. 85: 825-830.

26. Doe, R. P., P. Dickinson, H. H. Zinneman, and U. S. Seal. 1969. Elevated nonprotein-bound cortisol (NPC) in pregnancy, during estrogen administration and in carcinoma of the prostate. J. Clin. Endocrinol. Metabol. 29: 757-766.

27. Guidollet, J., and P. Louisot. 1969. Biosynthèse de la transcortine. II. Role des oestrogènes dans l'activation de sites moléculaires préalablement masqués. Acta Endocrinol. 62 : 468-476.

28. Guidollet, J., and P. Louisot. 1969. Biosynthèse de la transcortine. Localisation des sites fixateurs de cortisol et de cortecosterone dans les fractions sub-cytoplasmiques des cellules hépatiques du rat. Clin. Chim. Acta. 23: 121-132.

29. Lowry, O. H., N. J. Rosebrough, A. L. Farr, and R. J. Randall. 1951. Protein measurement with the Folin phenol reagent. J. Biol. Chem. 193: 265-275.

30. De Moor, P., K. Heirwegh, J. F. Heremans, and $M$ Declerk-Raskin. 1962. Protein binding of corticoids studied by gel filtration. J. Clin. Invest. 41: 816-827.

31. Muldoon, T. G., and U. Westphal. 1967. Steroid-protein interactions. XV. Isolation and characterization of corticosteroid-binding globulin from human plasma. J. Biol. Chem. 242: 5636-5643.

32. Ornstein, L. 1964. Disc electrophoresis. I. Background and theory. Ann. N. Y. Acad. Sci. 121: 321-349.

33. Davis, B. J. 1964. Disc electrophoresis. II. Method and application to human serum proteins. Ann. N. Y. Acad. Sci. 121 : 404-427.

34. Amaral, L., A. J. Samuels, and S. Werthamer. 1971. Transport of cortisol by cultured chronic lymphocytic leukemic lymphocytes. Experientia (Basel). 27 : 511-512.

35. Blackard, C. E., R. P. Doe, and U. S. Seal. 1973. Serum corticosteroid-binding globulin, cortisol, and nonproteinbound cortisol levels in patients receiving estrogen for carcinoma of the prostate. Invest. Urol. 11: 194-197.

36. Burstein, R. H., and H. T. Blumenthal. 1969. Immune reactions of normal pregnancy. Am. J. Obstet. Gynecol. 104: 671-678. 